Available online on 15.09.2016 at http://jddtonline.info
Journal of Drug Delivery and Therapeutics
An International Peer Reviewed Journal
Open access to Pharmaceutical and Medical research
C 2016, publisher and licensee JDDT, This is an Open Access article which permits unrestricted noncommercial use, provided the original
work is properly cited

\title{
SINGLE BLIND PLACEBO-BASED STUDY ON PREVENTION OF CORONARY ARTERY DISEASE (CAD) BY INJEER AND ISPAGHULA
}

\author{
${ }^{1}$ DR. Abdul Qudoos, ${ }^{2}$ DR. Shahina, ${ }^{3}$ DR. Khalid Niaz, ${ }^{*}$ DR. Shah Murad Mastoi \\ ${ }^{1}$ Pharmacology Department, FMDC Islamabad, Pakistan \\ ${ }^{2}$ Biochemistry Department, SBBMC, Pakistan \\ ${ }^{3}$ Pharmacology Department, IMDC, Islamabad, Pakistan \\ ${ }^{4} \mathrm{HOD} /$ Department of Pharmacology, IMDC, Islamabad, Pakistan
}

Received 14 June 2016; Review Completed 30 Aug 2016; Accepted 30 Aug 2016, Available online 15 Sep 2016

\begin{abstract}
Introduction: Injeer and Ispaghula are frequently/successfully used for treatment of both primary and secondary Hyperlipidemia. Major cardiac diseases are directly or indirectly linked with high levels of lipids in systemic circulation. Various medicinal herbs can normalize lipid profile of patients suffering from primary or secondary hyperlipidemia with or without metabolic syndrome. Place of research work: It was conducted at Jinnah hospital Lahore-Pakistan from January to May 2016. One hundred hyperlipidemic patients were enrolled for the research work.

Type of research study: This research work was single blind placebo-controlled.

Criteria for inclusion and exclusion: Primary or secondary hyperlipidemic patients of both gender, age range from 20 to 65 years were included in research. Patients suffering from any major organ disease like renal, hepatic, pulmonary diseases and already on drugs for major cardiac disease were excluded from the study.

Grouping of participants: Patients were divided in four groups, 25 patients in each group. Group-I was on Injeer, Group-II was on Ispaghula, Group-III was on combination of these two herbal medicines, and Group-IV was considered as control group.

Determination of TC, TG, LDL-C and HDL-C: Base line lipid profile was measured in Pathology Laboratory of JINNAH HOSPITAL.

Result compilation and biostatistical analysis: After three months therapy, their lipid profile was determined and mean values with \pm SEM were compared before and after treatment. When analyzed statistically and compared with placebo effects, all patients' LDL-cholesterol was reduced significantly. HDL-cholesterol was increased in all groups of patient.

Conclusion: Final conclusion of research work was that at specific concentration and period of ingestion of herbs like psyllium husk, and figs can reduce risk of hyperlipidemia leading to development of cardiac diseases, especially coronary artery disease.

Key-words: Single Blind Placebo-Based Study, Coronary Artery Disease, Injeer and Ispaghula

DOI: http://dx.doi.org/10.22270/jddt.v6i5.1279

URI: http://jddtonline.info/index.php/jddt/article/view/1279
\end{abstract}

\section{INTRODUCTION}

Why ratio of victimization of patients by cardiac problems is continuously steeped up is major focus of medical researchers now days. Sedentary life style, use of fatty foods, excessive alcohol use, primary/secondary hyperlipidemia, and smoking are major cause of cardiac diseases ${ }^{1}$. Free radical formation is consequence of these habits. These free radicals form atherogenic plaques and cause coronary artery disease. Hypertension, angina, congestive cardiac failure, myocardial infarction and cardiac arrhythmias are end stage of progression of coronary artery disease ${ }^{2}$. Formation of atherosclerotic plaques leading to develop $\mathrm{CAD}$ is due to presence of high plasma LDLcholesterol and lower plasma concentrations of HDL- cholesterol $^{3}$. Conventional method of hypolipidemic drug's therapeutic philosophy is going to be unpopular due to unwanted pharmacological effects of these drugs $^{4}$. At least in low economic human population, peoples are getting benefits from hypolipidemic medicinal herbs like Ispaghula and Injeer. Ispaghula seeds and husk decrease plasma cholesterol by two mechanisms. First ispaghula inhibit enterohepatic circulation of bile acids from gastrointestinal tract, leading to depletion of bile store in gall bladder, which signals hepatocytes to form bile acid instead of cholesterol synthesis. Second, ingested lipids are adsorbed with ispaghula and are excreted in $\mathrm{stool}^{5-8}$. Injeer or Ficus Carica or Figs has been used traditionally to treat various ailments such as 
hyperlipidemia, diabetes mellitus, gastric problems, inflammation, and cancer 9 . Injeer figs are rich in phenolics, organic acids, and volatile compounds. Regarding phenolics, numbering over 4,000 distinct species, many of these compounds have antioxidant activity. They may affect cell-to-cell signaling, receptor sensitivity, inflammatory enzyme activity or gene regulation, which play part to scavenge free radicals formed in many metabolic processes in human body ${ }^{10,11,12}$. Processed and dried figs are superior to natural figs when it comes to antioxidants ${ }^{13,14,15}$. Total and individual phenolic compounds, phenolic acid, chlorogenic acid, flavones, and flavonols, have been isolated from fresh and dried fig skins of Injeer. Dried Injeer contains higher amounts of phenolics than the pulp of fresh fruits. Phenolic acid, flavones and flavonols are antioxidant compounds present in fresh or in some dried fruits, vegetables, even in aesthetic plants. Medical researchers are keenly interested to do work on these herbs, so that they can recommend herbal medication to clinicians to get good drug and patient compliance $^{16,17,18}$.

\section{MATERIAL \& METHOD}

Jinnah hospital Lahore was place of this single blind placebo-based study conducted from January to May 2016. One hundred primary and secondary hyperlipidemic patients were selected for study. Patient's age range was from 20 to 65 years. Inclusion criteria were primary, secondary hyperlipidemic patients, without medical history of victimization of patient by any major cardiac disease like Angina, Congestive Cardiac Failure, Myocardial Infarction, and Cardiac Arrhythmias. Exclusion Criteria were any thyroid, renal, hepatic disease, alcohol users, chain smokers, and taking any medicine on regular basis. Written and explained consent was taken from all participants and approved by research ethics committee of the hospital. Patients were divided in four equal groups, comprising 25 patients in each group. Their baseline determination of lipid profile was made at Biochemistry laboratory of the hospital. Group-I was advised to take Injeer 10 grams daily in three equally divided doses. Group-II was advised to take 10 grams of Ispaghula daily in three divided doses before each meal for three months. Group-III was advised to take 10 grams Injeer and 10 grams Ispaghula in three divided doses daily for three months. Group-IV was advised to take one capsule (containing grinded wheat) with each meal time, thrice daily for the period of three months. They were advised to come for follow up monthly. Their lipid profile was measured monthly. After three months their lipid profile was measured. Results were compiled and statistically analyzed by using SPSS version 8.1.0.0 2012. Mean values of the tested parameters were expressed with \pm SEM and paired ' $t$ ' test was applied to determine significant changes in mean values before after treatment. P-value $>0.05$ was considered as non-significant change, p-value $<0.01$ was considered as significant and p-value $<0.001$ was considered as highly significant change in results.

\section{RESULTS}

Injeer decreased TG $33.2 \mathrm{mg} / \mathrm{dl}$, TC $25.9 \mathrm{mg} / \mathrm{dl}$, LDL-c $20.1 \mathrm{mg} / \mathrm{dl}$ and increased HDL cholesterol $7.7 \mathrm{mg} / \mathrm{dl}$ in 24 patients. Ispaghula decreased TG 33.2, TC 22.6, LDL cholesterol $17.8 \mathrm{mg} / \mathrm{dl}$ and increased HDL cholesterol $5.3 \mathrm{mg} / \mathrm{dl}$ in 24 hyperlipidemic patients. Injeer and Ispaghula when given in 22 hyperlipidemic patients, these herbs reduced LDL-cholesterol 25.7 $\mathrm{mg} / \mathrm{dl}$ and increased HDL-cholesterol $8.7 \mathrm{mg} / \mathrm{dl}$. Other biostatistically analyzed results are shown in following table.

Table 1: Effects of Injeer, Ispaghula and combination of these two herbs on Triglycerides, Total-cholesterol, LDL and HDL-cholesterol in three months therapy

\begin{tabular}{|l|l|l|l|l|l|l|}
\hline Herbs used & $\begin{array}{l}\text { Lipid } \\
\text { type }\end{array}$ & $\begin{array}{l}\text { At start of } \\
\text { study }\end{array}$ & $\begin{array}{l}\text { At end of } \\
\text { study }\end{array}$ & $\begin{array}{l}\text { Difference before } \\
\text { and after treatment }\end{array}$ & \% change & p-value \\
\hline Injeer (n=24) & TG & $199.11 \pm 1.88$ & $165.91 \pm 1.99$ & 33.2 & 16.7 & $<0.001$ \\
& TC & $302.33 \pm 1.11$ & $276.39 \pm 2.77$ & 25.9 & 8.6 & $<0.01$ \\
& LDL-c & $236.17 \pm 1.87$ & $216.08 \pm 1.66$ & 20.1 & 8.5 & $<0.01$ \\
& HDL-c & $40.05 \pm 2.19$ & $47.74 \pm 1.45$ & 7.7 & 16.1 & $<0.001$ \\
\hline Ispaghula & TG & $211.01 \pm 1.20$ & $177.78 \pm 1.12$ & 33.2 & 15.7 & $<0.001$ \\
(n= 24) & TC & $276.76 \pm 2.88$ & $254.15 \pm 2.28$ & 22.6 & 8.2 & $<0.01$ \\
& LDL-c & $228.76 \pm 2.91$ & $210.92 \pm 2.86$ & 17.8 & 7.8 & $>0.01$ \\
& HDL-c & $33.33 \pm 1.61$ & $38.60 \pm 2.10$ & 5.3 & 13.7 & $<0.001$ \\
\hline Combined & TG & $220.00 \pm 2.11$ & $190.08 \pm 2.16$ & 29.9 & 13.6 & $<0.001$ \\
herbs (n=22) & TC & $333.18 \pm 1.99$ & $312.11 \pm 3.87$ & 21.1 & 6.3 & $<0.01$ \\
& LDL-c & $234.65 \pm 3.76$ & $208.97 \pm 1.32$ & 25.7 & 11.0 & $<0.001$ \\
& HDL-c & $38.87 \pm 1.42$ & $47.54 \pm 2.86$ & 8.7 & 18.3 & $<0.001$ \\
\hline Control & TG & $154.11 \pm 1.92$ & $151.66 \pm 1.34$ & 2.5 & 0.9 & $>0.05$ \\
Group & TC & $222.15 \pm 3.31$ & $220.16 \pm 2.22$ & 2.0 & 0.05 \\
(n=25) & LDL-c & $221.97 \pm 2.10$ & $220.12 \pm 2.00$ & 1.9 & $>0.05$ \\
& HDL-c & $35.43 \pm 2.50$ & $36.19 \pm 3.76$ & 0.8 & 2.2 & $>0.05$ \\
\hline
\end{tabular}

KEY: All parameters and change in these parameters before and after treatment are measured in mg/dl, and their mean values are written with \pm SEM. P-value $<0.001=$ highly significant, $P$-value $<0.01=$ significant, $p$-value $>0.05=$ non-significant changes in lipid profile parameters tested. $n$ stands for sample size. TG stands for triglycerides, TC stands for total cholesterol, LDL-c 
stands for low density lipoprotein cholesterol, HDL-c stands for high density lipoprotein cholesterol. Combined herbs mean combination of Injeer and Ispaghula.

\section{DISCUSSION}

Many cardiac diseases are responsible for human morbidity and mortality all over the world. Allopathic drugs used in cardiac diseases, due to their toxic effects, have had proved laymen proverb 'cure is worst than illness'. So researchers are seriously taking interest in research work on medicinal herbs due to their lesser side effects. Ispaghula is well known, since long for its hypolipidemic and normalizing gastrointestinal motility. Fruit Injeer (Figs) are one of the earliest fruits grown by human beings in history. Though figs (Injeer) are not available throughout the year. Figs are used for digestion of foods, for treating hypertension, diabetes mellitus, anemia, obesity, bones deformity, and for prevention of complications leading to cause heart diseases like oxidative stress and Hyperlipidemia. Injeer or Ficus Carica or Figs contain flavonoids, various phytochemicals, wide variety of organic acids, furanocoumarins, polysaccharides. All these compounds have one way or other antioxidant effect. In our research Figs consumption by 25 hyperlipidemic patients for three months decreased LDL-cholesterol $20.1 \mathrm{mg} / \mathrm{dl}$, and increased HDLcholesterol $7.7 \mathrm{mg} / \mathrm{dl}$. D. Pal et al ${ }^{19}$ proved near to same results as ours. They mentioned mechanism of antioxidant activity of this herb that active ingredients present in injeer scavenge and use free radicals and prevent cell damage in body. E. R. Stadtman ${ }^{20}$ used combination of ispaghula husk and Figs and proved $30.1 \mathrm{mg} / \mathrm{dl}$ reduction in LDL-cholesterol. These results match with ours as in our observation; combination of two herbs reduced LDL-cholesterol $25.7 \mathrm{mg} / \mathrm{dl}$ and increased HDL-cholesterol $8.7 \mathrm{mg} / \mathrm{dl}$ in three months therapy by two herbs. E. A. Lissi et $\mathrm{al}^{21}$ used Injeer or Figs in 78 hyperlipidemic patients and proved that this herbal medicine reduced plasma total cholesterol 34.88 $\mathrm{mg} / \mathrm{dl}$, LDL-cholesterol $9.96 \mathrm{mg} / \mathrm{dl}$ and increased HDL-cholesterol $2.04 \mathrm{mg} / \mathrm{dl}$. These results are in contrast with our results. Reason to contrast in these two studies are due to selective patients in these researchers study as they only selected secondary hyperlipidemic patients and used 5 grams Figs for one week only. We proved LDL-cholesterol reduction 17.8 $\mathrm{mg} / \mathrm{dl}$ when ispaghula husk was used by 25 patients for the period of 3 months. HDL-cholesterol increased 5.7 $\mathrm{mg} / \mathrm{dl}$ in our patients. These results match with results of study conducted by Hossain $\mathrm{P}$ et $\mathrm{al}^{22}$ who proved $20.04 \mathrm{mg} / \mathrm{dl}$ reduction in LDL-cholesterol when they advised their patients to take ispaghula for 8 weeks. Verma SK et $\mathrm{al}^{23}$ used combination of Injeer or figs with ispaghula seeds in 12 patients and proved LDLcholesterol reduction only $8.07 \mathrm{mg} / \mathrm{dl}$, while in our patients this decrease was $25.7 \mathrm{mg} / \mathrm{dl}$. Obvious contrasts in results are due to sample size. Drewnowski A et $\mathrm{al}^{24}$ have proved in their study that ispaghula husk is better than seeds for interrupting enterohepatic circulation leading to synthesis of bile by hepatic cells instead of cholesterol.

\section{CONCLUSION:}

It was concluded from this work that lipid profile of hyperlipidemic patients can be normalized by taking specific herbs having antihyperlipidemic characteristics like psyllium husk and Injeer.

\section{REFERENCES}

1. Laguerre M, Lecomte J, Villeneuve P: Evaluation of the ability of antioxidants to counteract lipid oxidation: Existing methods, new trends and challenges. Prog Lipid Res 2007; 46:2482.

2. Heiss G, Tamir I, Davis CE, Tyroler HA, Rifkind BM, Schonfeld G, Jacobs DR Jr, Frantz ID Jr. Lipoprotein cholesterol distributions in selected North American populations: the Lipid Research Clinics Program Prevalence Study. Circulation. 2012; 61:302-15.

3. Kostapanos MS, Liamis GL, Milionis HJ, Elisaf MS. Do statins beneficially or adversely affect glucose homeostasis? Curr Vasc Pharmacol. 2010; 8:612-631.

4. de Amorin A, Borba HR, Carauta JP, et al. Anthelmintic activity of the latex of Ficus species. J Ethnopharmacol 2009; 64(3):255-8.

5. Sanchez-Moreno C: Methods used to evaluate the free radical scavenging activity in foods and biological systems. Food Sci Technol Int 2012; 8:121-37.

6. Gordon T, Castelli WP, Hjortland MC, Kannel WB, Dawber TR. High density lipoprotein as a protective factor against coronary heart disease: the Framingham Study. Am J Med. 2014; 62:707-14.

7. Jian-Ke An, Wen-Bo Wang, Ai-Qin Wang. Preparation and uses of Psyllium husk. Starch-Starke 2010; 62(10):501-7.

8. Rice-Evans CA, Miller NJ, Paganga G: Structure-antioxidant activity relationships of flavonoids and phenolic acids. Free Radic Biol Med 2011; 20:933-56.
9. Berry JD, Dyer A, Cai X, Garside DB, Ning H, Thomas A, Greenland P, Van Horn L, Tracy RP, Lloyd-Jones DM. Lifetime risks of cardiovascular disease. N Engl J Med. 2012; 366(4):321-9.

10. Hong Wang, Gu Chen, Dandan Ren, Shang-Tian Yang. Hypolipidemic Activity of Ispaghula. Phytotherapy Research 2014; 28(2):268-73.

11. Canal JR, Torres MD, Romero A, Perez C. A chloroform extract obtained from a decoction of Ficus carica leaves improves the cholesterolaemic status of rats. Acta Physiol Hung 2010; 87(1):71-6.

12. Fredrickson DS, Levy RI, Lees RS. Fat transport in lipoproteins-an integrated approach to mechanisms and disorders. N Engl J Med. 2013; 276:94-103.

13. Brensike JF, Levy RI, Kelsey SF, Passamani ER, Richardson JM, Loh IK, Stone NJ, Aldrich RF, Battaglini JW, Moriarty DJ, et al. Effects of therapy with cholestyramine on progression of coronary arteriosclerosis: results of the NHLBI Type II coronary intervention study. Circulation. 2014; 69:313-24.

14. Wei Liu, Boce Zhang, Qin Wang, Zhouhong Xie, Wenbing Y ao, Xiangdong Gaoand Liangli (Lucy) Yu. Effects of Sulfation on the Physicochemical and Functional Properties of Psyllium. Journal of Agricultural and Food Chemistry 2010; 58(1):172-79. 
15. Lyme WE, Sen YS, Paralu YT. Hypoglycemic action of an oral fig-leaf in type-II diabetic patients. Diabetes Research and Clinical Practice 2008; 39(1):1200-1211.

16. Sze-Yuan Chou, Po-Jung Chien and Chi-Fai Chau. Effects of Psyllium Hyrophilic Mucilloid in hyperlipidemia. Journal of Agricultural and Food Chemistry 2008; 56(22):1094-98.

17. Zeggwagh N.A., Moufid A., Khaldi A., Michel J.B., Eddouks M. Cardiovascular effects of Ficus Carica. Circulation 2010; 6(8):343-6.

18. Perez C, Domingues E, Torres MD. Hypolipidemic activity of an aqueous extract from Fig tree leaves. Pharmaceutical Biology 2009; 38(3):181-6.

19. Deb T, Ghosh A, Bhadra B, Drug utilization study in Pregnancy induced hypertension in a tertiary care teaching hospital, Journal of Drug Delivery and Therapeutics, 2014; 4(2):169-172

20. Stadtman ER. Herbal medicines used as hypolipidemic agents. Free Radical Biol. Med. 2012; 9:315-25.

21. Lissi EA, Salim-Hanna Pascual C, Del-Castillo M. Herbs and their biochemical characteristics. Free Radical Biol. Med. 20014; 18:153-58.

22. Hossain P, Kawar B, El Nahas M. Psyllium husk for lipids lowering effect. N Engl J Med 2014;356:213-5.

23. Verma SK, Jain V, Singh DP. Effect of husk, figs on blood lipids, fibrinolysis and total antioxidant status in patients with ischemic heart disease. APJTD 2012; 2 Suppl 2: 739-43.

24. Drewnowski A, Popkin BM., Walker EL, Tastor V. The nutrition transition: ne-w trends in the global diet. Nutr Rev 2011; 55:31-43.

\section{*For Correspondence:}

Dr. S Murad Mastoi, HOD-Pharmacology

Islamabad Medical \& Dental College, Islamabad-Pakistan

Email: shahhmurad65@gmail.com

Cite this article as:

Qudoos A, Shahina, Niaz K, Mastoi SM, Single blind placebo-based study on prevention of coronary artery disease (CAD) by Injeer and Ispaghula, Journal of Drug Delivery \& Therapeutics. 2016; 6(5):37-40

DOI: http://dx.doi.org/10.22270/jddt.v6i5.1279 